\title{
Algunas consideraciones sobre la reforma del clero regular en España (1800-1808)
}

\author{
Carlos María Rodríguez lópez-Brea
}

\section{LA MONARQUÍA BORBÓNICA Y LA REFORMA DEL CLERO REGULAR}

Hoy en día resulta inaceptable excluir a los religiosos de los fenómenos de transformación y cambio iniciados en Europa durante la segunda mitad del siglo XVIII. En efecto, si dentro de los claustros aparecieron algunas corrientes reformadoras que se decían herederas de la primitiva disciplina regular, las Monarquías ilustradas, dentro de su política centralizadora, se plantearon reducir y controlar más estrechamente la variopinta gama de monasterios, conventos, colegios y hospicios regentados por los religiosos. Circunstancias ambas que, como veremos a continuación, también iban a estar presentes en el caso español.

Las órdenes regulares habian dejado de ser aquellos institutos lozanos y exuberantes de siglos atrás; hacia 1800, la dejadez moral y el quebrantamiento de la disciplina formaban parte de la vida cotidiana en los claustros ${ }^{1}$. Tampoco las ideas y las políticas de la segunda mitad del siglo XVIII habían sido favorables para los religiosos. Si para los pensadores ilustrados el prototipo de "clero útil", difusor de los nuevos ideales racionalistas, era el párroco ${ }^{2}$, los frailes, por contra, encarnaban una religiosidad barroca y

\footnotetext{
Carrocera, Buenaventura de, La provincia de frailes M.M. Capuchinos de Castilla, Madrid, Centro de Propaganda, 1973. A pesar de la intención «propagandística» de su obra, Carrocera no puede evitar referirse a estos años con amargura. Explica este historiador que el general de la Orden capuchina, tras visitar la provincia de Castilla, «insistió en el más estricto cumplimiento de la observancia regular, y de modo especialisimo en todo cuanto dice a los votos de obediencia y pobreza". "Fácilmente se advierte - afirma Carrocera- el ambiente nada propicio para desenvolverse la vida religiosa de las comunidades castellanas en las postrimerías del siglo XVIII", vol. II, pág. 278.

2 DOMINIQUE, JULIA, "El sacerdote», en Michel Vovelle (ed.), El hombre de la llustración. Madrid, Alianza Editorial, 1995.
} 
fanática con la que había que acabar. En el terreno político, el emperador José II de Austria había llegado a reformar y suprimir algunos conventos sin recurrir siquiera a la Santa Sede ${ }^{3}$. Este regalismo, según el cual la autoridad civil tenía el derecho y el deber de intervenir en los asuntos de disciplina eclesiástica, era también compartido por los ministros de Carlos III: la supresión de la Compañía de Jesús en los territorios españoles en 1767 respondía a esta lógica. Pero la política de Carlos III no estuvo tanto orientada a la reducción de las órdenes, como a su mayor control ${ }^{4}$; el principal objetivo, según confesaba Floridablanca en la llamada «Instrucción Reservada», era separar la rama española de las órdenes regulares de su tronco romano:

"La tercera pretensión con la Curia Romana podrá ser la de reducir todas las familias religiosas a una disciplina más conforme a su Instituto y al bien del Estado, y obtener que todas tengan superior nacional dentro del reino, el cual pueda cuidar de cerca de la misma disciplina, ser responsable de sus negligencias y relajaciones, evitar extravios y gastos de viajes a países extranjeros, con motivo de recursos y capitulos, y tener amor y celo por mi servicio, y por el bien de la patria».

Para los ministros carolinos no era admisible que otra potencia, Roma, controlara las voluntades de unos religiosos que a fin de cuentas eran españoles, y como tales, súbditos del rey. Por eso, la «Instrucción Reservada» recomendaba también que «la autoridad real intervenga, por vía de protección, en la elección y nombramiento de estos superiores regulares, y no se elijan los que no sean gratos al soberano " 5 .

Después de algunos años con avances modestos, la administración de Godoy volvía a plantearse la reforma del clero regular. Con esta finalidad, y aprovechando una coyuntura diplomática favorable, la Corte española

3 José II, por un edicto imperial de 1782, suprimió las casas religiosas de cartujos, benedictinos camaldulenses y eremitas, y las ramas femeninas de capuchinos, carmelitas y franciscanos, esto es, unos 700 conventos en total. Ese mismo año el Emperador promulgó el Reglamento general en torno a la disciplina del clero regular, que debia aplicarse a la Lombardía: este reglamento venía a ser la máxima expresión de la vía regalista de la reforma de regulares. Furio Díaz. Europa: de la llustración a la Revolución. Madrid, Alianza, 1994, págs. 502-504 y Juan María Laboa, "La estructura eclesiástica durante la época moderna» en RICARDO GARCÍA VILLOSLADA y JUAN MARÍA LABOA (ed.), Historia de la Iglesia Católica. IV'. Edad Moderna. La época del absolutismo monárquico (1648-1814). Madrid, B.A.C., 1991, págs. 193-259, y especialmente, págs. 283-245.

4 CASTRO, CONCEPCIÓN DE, "Campomanes y el clero regular", en Actas del Congreso Internacional "Carlos III y la llustración». Madrid, 1989, tomo II, págs. 467-485.

5 "Gobierno del Señor Rey Don Carlos III o Instrucción Reservada para la dirección de la Junta de Estado que creó este Monarca" de 1787, atribuida al conde Floridablanca, B.A.E. Volumen CXV, especialmente págs. 306 y 307. 
iniciaba en 1800 las negociaciones directas con el papa; se descartaba, por tanto, la vía regalista por cuanto la intervención unilateral del Estado en materias eclesiásticas era fuente de continuas tensiones con la Iglesia. La primera petición que planteó la Corte española fue la sujeción de los religiosos a los obispos, en vez de a sus superiores generales, lo que significaba una reforma en toda regla de la disciplina regular, pero Pío VII sólo consintió en delegar algunas facultades apostólicas en el arzobispo de Toledo, que a la sazón era el cardenal Luis de Borbón, primo del monarca. Dicha delegación autorizaba al cardenal para la visita «por una vez» de las provincias regulares de España, esto es, "Monasterios, Colegios, Casas, Iglesias, Hospicios (...) aunque sean exentos y estén distinguidos o asistidos de cualquier privilegio o indulto» y para promover algunas reformas menores, ya que en las materias de "mayor gravedad", es decir, "aquellas que pidan unas innovaciones generales y perpetuas», el pontífice se reservaba la decisión final ${ }^{6}$. Parecía que Pío VII, conocedor de que la visita encomendada al cardenal sería necesariamente lenta (por cuanto tenía que hacerse convento a convento), esperaba la venida de tiempos mejores para la Santa Sede, muy debilitada esos años por la política de Napoleón. Así lo interpretó el por entonces canónigo de la catedral de Toledo y futuro obispo, José Jiménez: «yo creo que esta comisión la impuso la política más fina de Roma, o para impedir la ejecución a lo menos de algo de lo que se pide por nuestra Corte o para entorpecerlo esperando coyuntura más favorable para arreglarlo» ${ }^{7}$. Por su parte, el embajador español en Roma, Vargas Laguna, ducho en estas lides diplomáticas, consideraba inviable la sujeción de los religiosos a los obispos: «creo, señor -escribe Vargas a Godoy-, imposible la total reintegración de los obispos con consentimiento de esta Corte». Y es que la Curia romana no aceptaba que los problemas del clero regular pudieran estar motivados por la independencia de los Obispos: «la Congregación y el Santo Padre -informaba Vargas- atribuían los desórdenes más bien a la relajación que el largo curso de los tiempos ocasiona en todos los establecimientos humanos que a la independencia" ".

Es posible que en el contexto de la negociación, la corte española presentara una oferta imposible de aceptar por el Papado, y así encontrar una mejor disposición ante nuevas reivindicaciones. De hecho, tras fracasar

Texto del Breve de 10 de septiembre de 1802. A.H.N., Consejos, leg. 4.035.

AGDT (Archivo General Diocesano de Toledo), Fondos Religiosos, leg. «Visita Apostólica de 1802". Carta del canónigo José Jiménez a Sebastián Gorbea, 14 de noviembre de 1802.

8 AGDT, loc cit. Carta de Vargas Laguna a Godoy, 10 de septiembre de 1802. 
este primer intento, la corte borbónica pidió al papa la creación de Vicariatos Nacionales en todas las órdenes regulares españolas, o lo que es lo mismo, la independencia de las religiones españolas de su tronco romano. Carlos IV, en un memorial remitido al pontífice, aseguraba que era inviable la reforma del clero regular encomendada al cardenal de Borbón ( «la Visita universal celebrada en conformidad a la Bula de Su Santidad (...) ha de ser lentísima por la multitud de conventos y enorme distancia de ellos entre sí, especialmente en las Américas"), por lo que habría que pensar en una nueva alternativa: «la creación y establecimiento de vicarios generales nacionales que residan en España en las órdenes que no los tienen, para el buen régimen de ellas y mejor observancia en sus constituciones; y para la tranquilidad de los frailes particulares, que de otro modo están expuestos a sufrir violencias sin arbitrio para evadirse de ellas" ${ }^{9}$.

La primera reacción de la Curia romana ante esta nueva propuesta fue muy negativa. Pío VII, airado por las continuas reivindicaciones de la Corte española, llegó a decir a Vargas Laguna que «una variación semejante carecía de ejemplo y su aprobación, sobre hacerlo odioso, ocasionaría que las demás Cortes solicitasen iguales reformas sin que hubiese arbitrio para negárselas hecho una vez el ejemplar con la de España». El papa amenazó con dilatar indefinidamente el asunto, y llegó a recordar incluso que la separación de los dominicos y escolapios españoles de su rama romana, concedida por breve en 1801, estuvo «movida del deseo de evitar (concediendo algo) que se estrechase más sobre las Dispensas matrimoniales, y las facultades del nuncio y de los obispos" ${ }^{10}$. Pío VII tan sólo aceptaba la alternativa en el Generalato de las órdenes (esto es, que se sucedieran un general español y otro extranjero), una fórmula aplicada en la familia franciscana desde el siglo XV ${ }^{11}$, pero Godoy no parecía conformarse con esta oferta:

«la alternativa del Generalato -escribió a Vargas Laguna- (...) sería por sí sola ineficaz para la absoluta extirpación de la relajación y desórdenes que demuestran e inutilizan las Religiones, porque sólo curaría a medias (...)

9 Un excelente análisis del Memorial remitido por el Rey al Papa, con fecha de 30 de mayo de 1803, en Basilio de RuBi, Reforma de regulares en España a principios del siglo xix. Estudio jurídico de la Bula «Inter Graviores» (15 de Mayo de 1804)». Barcelona, Librería Bosch, 1943, págs. 44-47. Hemos completado la perspectiva de Rubí con la documentación conservada en AGDT, loc. cit. y que permanece inédita, que sepamos.

10 AGDT, loc. cit. Vargas Laguna a Godoy. No olvidemos que la negociación sobre la reforma del clero regular fue paralela a otras concesiones del Papado a la Corte española, tanto en materia económica (principalmente diezmos y desamortizaciones) como en materia espiritual (pase regio al Breve del nuevo Nuncio, Pietro Gravina).

11 Así lo confirmaba Vargas Laguna: "Un sistema de alternativa -escribió el embajador a Godoy - fue el que Su Santidad anunció confusamente». 
Su zelo [de S.M.] no se dará por satisfecho con respecto a los regulares mientras no tengan en España superiores con toda la autoridad competente para desarraigar las causas que han producido como efecto necesario la decadencia en que están» ${ }^{12}$.

Cuando todo parecía perdido, el cardenal Consalvi, secretario de Estado de Pio VII, y el embajador Vargas Laguna llegaron a un principio de acuerdo que, en líneas generales, anticipaba la futura Bula Inter Graviores: a la alternancia en el generalato por seis años, inicialmente aceptada por el Papa, se sumaba ahora la creación de un vicario general español durante el sexenio en que el General de la orden fuera extranjero, vicario que seria elegido por los miembros españoles del capítulo general. A resultas de esta fórmula, las provincias regulares españolas quedarían alternativamente gobernadas por un general español, obligado a residir en España, y por un vicario general, con las mismas facultades que el general o supremo presidente de la orden ${ }^{13}$. Vargas Laguna comunicaba a Godoy, por vía reservada, los detalles de una negociación en la que las trampas y los engaños no estuvieron ausentes; el embajador español se vanagloriaba incluso de haber utilizado dos falsas presunciones ante el pontífice:

«Primera, en suponer que muchos de los Cardenales consultados habían sido favorables, y por consiguiente que la negativa del Papa era absolutamente voluntaria. Yo había indagado todo lo contrario, pero como el decreto de Inquisición se impone en tales casos [aquí Vargas se refiere al secretismo con que la Corte romana solía conducir este tipo de negociaciones] impedía que me le convenciere de hecho; a el voto indeciso de dos cardenales y a mi afirmativa ley di una fuerza que no pudieron resistir.

La segunda afirmativa consistió en decir que yo no podia menos de instruir a un soberano de cuanto había llegado a entender y de la falta de palabra y aun contradicciones con que se habia procedido en un asunto que sólo con sofismas se podía rebatir cual lo demostraban las razones en que se fundaban los Breves últimamente presentadas y mis diversas notas. Que S.M. viendo convertida en odio su consideración con la Santa Sede era regular se ofendiese altamente y causado de sufrir males a quien no se trata de poner remedio, por más que lo desea y pide por los medios más decorosos para Su Santidad los cortase de una vez usando de sus facultades, y declarando todos los Regulares sujetos a sus respectivos obispos. Estas

AGDT, Ioc. cit. Godoy a Vargas Laguna, 27 de julio de 1803.

3 El 29 de julio de 1803 se redactaba un primer esquema de la Bula, definitivo en lo sustancial. El primero y el segundo esquema de la Bula, en Basilio de RuBí, op. cit, págs. 51-56. Este autor, siguiendo la rica documentación del Archivo Vaticano, destaca de manera especial el papel de Consalvi en ei desarrollo de las negociaciones, minusvalorando quizá la labor del otro negociador, Antonio Vargas Laguna. 
afirmaciones hechas con toda entereza y con un semblante tan halagüeño como el mío cuando se halla exaltado produjeron el trastorno de todas sus ideas $(\ldots)$.

Los romanos se comparan comúnmente a la alcachofa, que pelada de un golpe espina la mano y obliga a arrojarla, pero mondada hoja por hoja presenta el cogollo sin ofensa de la mano que lo busca y se lo deja arrancar para que la misma mano lo lleve a la boca (...) es indispensable herir a estas gentes con sus propias armas y hacerles tragar dulcemente el anzuelo» ${ }^{14}$.

Aunque la Corte hispana había conseguido una mayor autonomía para las órdenes regulares españolas, no se rompía totalmente la dependencia de éstas con su tronco romano. Ciertamente, el secretario del cardenal de Borbón, Sebastián Gorbea, escribió a Godoy en tono triunfalista que «no habrá en lo sucesivo real y verdaderamente dependencia alguna de los generales extranjeros" ${ }^{15}$, pero como ha demostrado Basilio de Rubí la pretendida emancipación de las religiones españolas no fue tal puesto que la jurisdicción de cada vicario español sobre sus religiosos no era propia, sino sólo una delegación de las facultades del general ${ }^{16}$; además, se advertía que «en los negocios de mayor entidad concernientes al gobierno espiritual de la orden, y a la disciplina, el vicario general, para proceder de un modo más acertado y seguro, y a fin de que en toda la Orden se conserve la substancia del Instituto, deberá consultar al presidente supremo» ${ }^{17}$.

La institución de un Vicariato Nacional fue muy desigualmente recibida. La satisfacción en la Corte española fue compartida por el cardenal Borbón y su círculo ${ }^{18}$, pero entre el clero regular, y muy particularmente entre los prelados, la opinión fue mucho más matizada. Por ejemplo, el padre Millán Santísima de la Cruz Poves encontraba en este vicariato el germen de nuevas discordias en los claustros:

«Serían los Vicarios Generales como unos Provinciales, o poco más, y faltando el freno del correspondiente respeto havría muchas disputas,

14 AGDT, Ioc. cit. Carta de Vargas Laguna a Godoy por vía reservada, $1^{\circ}$ de agosto de 1803.

15 AGDT, Ioc. cit. Carta de Sebastián Gorbea a Godoy, 28 de Octubre de 1803.

16 RuBí, op. cit., págs. 97-101.

17 Texto del Breve Inter Graviores, de 15 de Mayo de 1804.

18 El cardenal Borbón escribía años después que «al principio de mi Visita reconocí la necesidad de instituirlos [los Vicarios Nacionales] para el régimen de las órdenes establecidas en los dominios de España con independencia de las otras provincias existentes fuera de ella y habiéndolo manifestado así a Su Santidad tanto el Rey nuestro Señor como yo, tuvo la dignación de acceder a esta propuesta por su Breve Inter Graviores del 15 de mayo de mil ochocientos quatro, estableciendo reglas seguras y perpetuas para su elección". AHN, Consejos, leg. 12.078. Informe del Cardenal Borbón a la Regencia, 10 de julio de 1810. 
disensiones, pleytos y recursos. Havría parcialidades entre los Vicarios Generales, sus amigos contemporáneos, discípulos, condiscípulos, paysanos y bienhechores, de todo lo qual se halla muy ajena una cabeza general que mira con independencia las Provincias y libre de enlaces particulares atiende solamente a lo justo y mira por su honor con la igualdad de su govierno en todas las Provincias ¿Y qué sería el fuego de los partidos que se encendería para las elecciones?».

El provincial franciscano Francisco Gómez, por su parte, consideraba que la autoridad de los superiores provinciales quedaría deprimida con el nuevo orden de cosas: "se añadirían las correspondientes disputas y pleitos del Vicario general con los provinciales sobre la jurisdicción y la autoridad que a cada uno compete; siendo muy fácil el recurso o recursos de los súbditos al vicario, sin motivo ni fundamento" ${ }^{19}$. El célebre dominico Francisco Alvarado, algunos años más tarde, recordaba el disgusto con el que muchos religiosos recibieron la creación de estos nuevos vicarios:

"Ya Ud. se acordará -escribía en sus célebres Cartas Críticas- de la novedad que se hizo en varias religiones cuando por disposición del príncipe Godoy, y a consulta de su consejo, se impetró bula para que en todas se estableciesen vicarios o generales nacionales. Yo llevé muy a mal esta determinación, y luego que la vi ejecutada, peor, teniendo por compañeros a muchos frailes que parecian de razón y que efectivamente lo eran» 20.

De esta forma, y no sin polémicas, se iniciaba un nuevo régimen de gobierno entre los regulares españoles. Un nuevo régimen querido y buscado por la administración de Carlos IV, pero no por muchos de los prelados de las religiones, siempre celosos de su independencia, ni por los religiosos más radicalmente reformistas que, como veremos a continuación, abogaban por otro tipo de cambios.

\section{REFORMISMO DENTRO DEL CLERO REGULAR}

Una vez descrita la reforma amparada desde el poder político, conviene analizar algunas de las actitudes de los religiosos españoles ante la problemática del clero regular. En este sentido, el cardenal de Borbón,

\footnotetext{
19 AGDT, 10c. cit., «Encuesta del Cardenal Borbón sobre la reforma». Testimonios de Millán Santísima de la Cruz Poves (28 de noviembre de 1802) y de Francisco Gómez (1804).

20 Alvarado, Francisco, "Filósofo Rancio", Cartas Críticas, Madrid, Imprenta Aguado, edición de 1824-25. Carta XXXI, 18 de febrero de 1813. Vol. III, pág. 248 (el número de carta corresponde a la numeración de la edición relerida).
} 
quiso conocer la opinión de algunos prelados significados sobre la decadencia de los regulares ${ }^{21}$. El franciscano Agustín García Porrero, especialmente benévolo con los religiosos («estos males - decía- no son ciertamente tan universales como se suponen»), insinuaba que las dificultades del clero regular no tenían su origen en el interior de los claustros:

"Háganse las más inequívocas diligencias, y las más rigurosas Visitas, y se hallará que en todas y en cada una de las Ordenes Religiosas hay muchos varones llenos de providad, de virtud, de zelo, observantísimos de sus Reglas y zelosisimos de la disciplina monástica, que con su doctrina y vida exemplar condenan las máximas del mundo y aborrecen los negocios y los bullicios del siglo. Acaso, y sin acaso, si no huviera en los claustros tantos hombres de virtud y sabiduría, no tendrían las órdenes religiosas tantos enemigos".

Para el dominico Francisco Gómez las relajaciones, existiendo, no afectaban a la sustancia de la vida religiosa. La decadencia, pensaba "no parece transcendente a los puntos substanciales que constituyen el Estado religioso, se reduce solamente a ciertas mitigaciones en el rigor de la disciplina, retiro, ayunos y otras circunstancias de esta clase»; por el contrario, los religiosos, "lejos de haber abrazado algunas opiniones nuevas y peligrosas (...) han sido y son los que rebaten y han rebatido con todo el esfuerzo posible las peligrosas novedades de este siglo, contrarias muchas de ellas a la Religión y al Estado». Para el padre Gómez no sería tan preocupante la relajación disciplinar como la difusión de doctrinas heterodoxas, y éstas tenían un poderoso dique en la vida regular: "se sabe - afirmaba - que casi todas las Religiones en el día siguen la doctrina de Santo Tomás, de Escoto, y otros autores discípulos de estos; consta igualmente la reforma de la moral christiana, introducida principalmente por los Religiosos y continuada hasta la perfección, en que al presente se halla». Otro prelado, fray Domingo Moreno, inicidía en que la relajación afectaba de manera desigual a unos y otros: «observamos más decadencia en la disciplina regular en unas Religiones que en otras: más observancia en unas Provincias que en otras de una misma Religión, más en unos Conventos que en otros de una misma Provincia", por lo que consideraba óptima la vía reformista autorizada por el Papa en el Breve de 1802: «la decadencia en la disciplina regular no procede de causas generales i notorias

21 Fueron consultados los padres Francisco Gómez, Agustín García Porrero, Juan Antonio Fernández y Domingo Moreno. También se pidió la opinión de Rafael Antón de la Encina, clérigo secular, que poco después sería secretario del cardenal Borbón, del licenciado Luis Mulet y de Bernabé Navarro. 
contraidas a las Religiones i transcendentales a todas ellas i cuya verdad se haría manifiesta con la visita o examen de cada Religión, de cada Provincia, de cada convento en particular».

El más explícito de todos los prelados consultados por el cardenal Borbón fue el mercedario fray Juan Antonio Fernández, que culpaba de la situación del clero regular a todos. Ciertamente, los religiosos habían abandonado el fervor primitivo que acompañó a los fundadores de las religiones («va insensiblemente decaiendo la observancia de aquellos individuos que no están íntimamente penetrados del espíritu de religiosidad y retiro»), y se enzarzaban en inútiles disputas internas durante las elecciones, a causa de «la ambición de los religiosos pretendientes» y «el espíritu de partido», pero en el decir del padre Fernández, tampoco la Corte española y la Curia romana estaban libres de culpas. La Corte por «la facilidad con que las quejas de los súbditos contra sus Prelados se oien en los Tribunales de S.M.», ya que el abuso en estos recursos de fuerza «enerva y debilita la autoridad de los Prelados, ataca del modo más activo el voto de obediencia, haciendo insolentes a los súbditos». La Curia romana también tendría su parte de responsabilidad por «los muchos Breves de secularización que se impetran de Roma de treinta a cuarenta años a esta parte»; «cada uno de estos Breves - añadía- es un poderoso aliciente para que los flacos instigados del mal exemplo pretendan substraerse del iugo de la obediencia». Tampoco olvidaba el padre Fernández referirse a "la general corrupción de costumbres en que está sumergida el mundo» 22.

Si el cardenal Borbón buscaba aclarar sus ideas con estos testimonios, poco pudo sacar en claro. Todos los prelados matizaban la gravedad de la situáción o, en caso de reconocerla, la atribuían a causas ajenas a los claustros. Tan sólo el padre Fernández parecía dispuesto a aplicar el bisturí, pero justo en la dirección contraria a la que marcaba el espíritu de los tiempos: ni secularizaciones ni intervención del poder político. Además, los prelados creían que la situación sólo podría mejorar si se aplicaran los cauces disciplinarios contemplados en los estatutos de las religiones, sin necesidad de recurrir a reformas excepcionales.

A pesar del interés de estas declaraciones, la opinión del conjunto del clero regular sobre su reforma resultaba mucho más compleja. En este sentido, hemos localizado los testimonios de algunos religiosos

22 Los testimonios en AGDT, loc. cit. Agustín Garcia Porrero (7 de diciembre de 1802), Francisco Gómez (22 de marzo de 1803), Domingo MoReno (12 de enero de 1803) y JuAN ANTONIO FERNÁNDEZ (31 de diciembre de 1802). 
que no ocupaban cargos de responsabilidad, cuya visión del problema es bien distinta ${ }^{23}$. Citaremos los ejemplos más significativos. Una primera representación, firmada por tres religiosos, formulaba que las órdenes regulares, decaídas por «la suma decadencia y notoria relajación», sólo podrían recuperar su lozanía retornando «a aquel estado de perfección y santidad sobre que las fundaron los santos fundadores», y de esta forma, "ser útiles a la Iglesia, al Estado y a la república», y no «el oprobio y desprecio de las gentes». Las causas genéricas de la decadencia serían el despotismo de los superiores, las profesiones a edad temprana, el espíritu de partido y el bajo nivel moral del clero regular («nos dejamos ver en los teatros públicos de toros, comedias, bailes y paseos públicos con que nos hemos llegado a igualar con los seglares más libertinos», mientras que otras veces salen de los conventos sólo «para galantear y cortejar»). La solución sería «arrancar la cizaña del trigo", esto es, reducir el número de frailes y de conventos: "la supresión de conventos es útil - concluían-; más vale pocos y buenos que muchos» 24 .

Fray Hilario de Ibiza opinaba que «el único remedio que tiene la presente relajación es volver el estado regular a su sistema antiguo»; un sistema antiguo que consistía en la supresión de grados y distinciones («la Santa Igualdad»), y en la sujeción de los religiosos a los Obispos. La celebración de capítulos y elecciones, a juicio del padre Ibiza, estaba en el origen de muchos de los males: «¿Quién ignora -escribía- que los capítulos no son otra cosa que una palestra de vergüenzas y de calumnias y una feria de simonías?»; la elección de los prelados, añadia, "es lo que por tres y seis años y por toda la vida trae ocupados, inquietos e incapaces de fijarse de las cosas de Dios a todos los pretendientes, sean Prelados locales o no Prelados (...) lo dicho es fomento de infinitas intrigas y el motivo de los infinitos regalos que (tal vez por agravio de conciencia, no sólo por los fines, si todavía por los medios) se hacen frecuentemente a los Generales y Provinciales». Si se suprimieran los superiores y, en su consecuencia, los religiosos pasaran a depender de los obispos, se pondría término a este frenesí ${ }^{25}$. Fray Tomás lbáñez, en términos prácticamente idénticos, pedía al cardenal Borbón el final de los capítulos provinciales: "Mande V.Emª que no se celebren Capítulos

23 Todos estos testimonios se conservan en A.G.D.T., leg. «Representaciones pidiendo la reforma".

${ }^{24}$ AGDT, «Representaciones...". Fray A. de Santa Cruz, Fray J.P० y fray P.M.1. ¿1803?

25 AGDT, «Representaciones...». Fray Hilario de Ibiza, sin fecha. 
Provinciales. Los capítulos son causa de relaxación. Cuatro meses antes de celebrarse, envía el Rmo. Padre General la convocatoria, y desde este instante, se mueven los frailes y se sueltan: los Presidentes todo lo dispensan, en el instante en que los Comendadores se ponen en camino. En el convento en que se celebra el Capítulo es indecible el desorden, en comidas, en regalos y en el mucho dinero que se atraviesa: la simonía saca la cabeza» ${ }^{26}$. "La celebración de Capítulos Provinciales y Generales, la promoción a los grados y nombramientos de los Prelados locales son la pobreza de los Conventos y riqueza del General», opinaba otro religioso partidario de conferir los grados por antigüedad para acabar con la corrupción: “los superiores no quieren esto - añadía-, pero Dios sí». No faltó quien denunciase la existencia de turbios manejos económicos: «los Prelados toman cuantas Misas pueden aunque sean millones de ellas, y saben muy bien que no pueden aplicarlas, y de 15 a 20 mil que tomen, apenas se aplican 300 ó 400. Para que alguna Visita Apostólica no lo sepa, ponen en los libros: recibí tanto de Misas, sin poner el número de ellas. De este dinero de misas que no se aplican, se da porción y no pequeña en visitas y fuera de ellas a los superiores para que otra vez los hagan Prelados, se hacen obras de conventos, se regalan Prelados y además guardan un gran bolsillo, para gastar toda su vida» ${ }^{27}$.

«Ha llegado el tiempo - decía otro religioso - de estar todo corrompido y que desde la suprema hasta la más ínfima prelacía, todo se confiere no según el espíritu de la religión, sino por pretensiones». Sus soluciones no diferían de las sugeridas por los anteriores: suprimir los generalatos y provincialatos, sujetar los regulares a los obispos, elegir prelados locales bajo estrecha vigilancia episcopal, y reducir el número de monasterios y conventos: "es muy útil (como diferentes veces se ha divulgado) el menorar de conventos dejando en cada pueblo sólo aquellos que sean útiles y suficientes a su vezindario» ${ }^{28}$. Un anónimo escrito bajo el seudónimo «la Religión Mercenaria” planteaba la dicotomía entre unos prelados ricos y unos religiosos empobrecidos por los gastos de las elecciones y de las visitas de los provinciales, «mui gravosas y sin ninguna utilidad a los

\footnotetext{
26 AGDT, «Representaciones...» Fray Tomás ibáñez Puche, 20 de abril de 1803.

27 AGDT, leg. Mercedarios 1. Sin fecha, aunque por su referencia a la Visita Apostólica se colige que es un testimonio algo posterior a los anteriores.

28 AGDT, «Representaciones..." Anónimo fechado en 1803 ("el que escribe omite su firma porque no merece contestación y sólo le suplica no omita su lectura"). También fray Diego Pérez de San Juan aseguraba que "sería lo mejor que todas las religiones se sujetaran a los Obispos y se quitaran sus superiores" (5 de junio de 1803).
} 
conventos» ${ }^{29}$. El también mercedario fray Bernardo de Almanzora llamaba a los prelados «marqueses y duques de su religión», y con cierto gracejo señalaba que "para Visitador de estos conventos no sería proporcionado alguno que gustase de banquetes y besamanos: se necesita un ruso acostumbrado a comer hombres y que sea capaz de postrar y desmenuzar estos Ydolos colosales que hai levantados en las religiones sin más fundamento que el sórdido sistema que rige en ellas para ser la ruina de la disciplina monástica» ${ }^{30}$. Fray Luis de Campos, franciscano de Murcia, denunciaba las costumbres del provincial de su orden, que «lleva una berlina con dos pares de mulas, con unos gastos excesivos", mientras que los prelados locales, cegados por la ambición, dejaban desamparados a sus súbditos: "el despotismo y la codicia de los prelados locales llega a tanto que por atesorar no quieren socorrer a los súbditos, dándoles libertad para que ellos mismos busquen como puedan" ${ }^{31}$.

Otros religiosos denunciaron que los prelados se apoyaban en banderias y facciones para conseguir el triunfo en las elecciones, pero despreciaban a aquéllos que no pertenecían a su facción. Un religioso de Écija escribía que «los superiores son despóticos y tratan a los frayles como esclavos. En llegando a ser superior, se conserva siempre en el mando y sólo acomoda a los de su familia y facción, o vando, dejando a los veneméritos que han trabajado, sin acomodo y persiguiéndoles, por no ser de los suyos". Los frailes sólo obedecían por miedo, porque de no ser así, afirmaba, "los meterían en la cárcel y les harían causa" ${ }^{32}$. Un hospitalario de San Juan de Dios se expresaba en estos mismos términos contra sus jerarcas: «viven tratando a los religiosos no como a hermanos y sí como a esclavos, llegando tanto su osadía hasta ponerles las manos violentamente sin poder éstos quejarse" ${ }^{33}$.

El franciscano Blas Ortiz, expresaba su confianza en la Visita Apostólica encomendada al cardenal de Borbón, "obra inspirada por Dios", a la par que exponía un sombrío panorama de su orden:

29 AGDT, «Representaciones...", Anónimo «La Religión Mercenaria», sin fecha (¿1803?). Aunque el anonimato de algunas de estas representaciones pudiera mover a algún historiador a dudar de su veracidad, consideramos, por contra, que el propio contenido de estos escritos muestra una realidad contrastada con otros testimonios. Algunos religiosos utilizaban el anonimato para evitar posibles represalias de sus superiores.

30 AGDT, "Representaciones..." Fray Bernardo, mercedario de Almanzora, 24 de abril de 1803.

AGDT, "Representaciones...". Fray Luis de Campos, Mula, 24 de mayo de 1803.

AGDT, "Representaciones...". Fray Antonio de San Pedro, Écija, 2 de junio de 1803.

AGDT, «Representaciones...». Anónimo de San Juan de Dios, Ronda, sin fecha. 
«nada quedó - decía- de aquella mente seráfica, pues sólo el dinero es el que reina, principalmente en los superiores y demás que gobiernan. Los empleos sólo se dan por lo común por la plata y oro y empeños. Los prelados locales son tan escasos en el socorro de las necesidades que por enriquecerse ellos, les dicen a los súbditos que busquen (...) unos son señores y otros esclavos, unos ricos y otros pobres".

Entretenidos con sus disputas, los frailes descuidaban una de sus principales obligaciones cual era la asistencia al coro: «los coros -aseguraba-, donde se pagan a Dios las Divinas alabanzas, están desiertos, pues los más son dispensados" ${ }^{34}$. "Todos los que pretenden empleos -afirmaba otro religioso- es por no hacer nada, ni ir al coro» ${ }^{35}$.

Basándonos en los testimonios de prelados y súbditos, podemos sintetizar los principales males de las religiones en estos tres puntos:

1. Se había descuidado el cumplimiento de la regla regular. Los religiosos vivían "en el siglo", participaban de diversiones mundanas y acudían con menor frecuencia al coro. El incremento de las secularizaciones denunciado por algún prelado sería un buen reflejo de esta "crisis de la conciencia” claustral.

2. Los prelados tenían problemas para imponer su autoridad. Si éstos atribuían la indisciplina a la facilidad con que «los frailes díscolos» presentaban recursos de fuerza ante la potestad temporal, los súbditos denunciaban las prácticas despóticas de sus superiores.

3. Las comunidades religiosas estaban divididas en facciones por la búsqueda de cargos, prebendas y honores. Las élites directivas conseguían perpetuarse formando partidos.

La decadencia de la vida regular planteaba diversas respuestas. Si para los prelados consultados por el cardenal Borbón no era necesario recurrir a cauces extraordinarios, la administración de Godoy, conforme a sus propósitos centralizadores, consiguió encauzar el problema del clero regular de una manera favorable a sus intereses, ya que los nuevos vicarios nacionales, propuestos por la Corona española, venían a ser una especie de funcionarios reales. Pero los testimonios procedentes del clero regular medio y bajo, hasta ahora ignorados, nos sugieren unas pautas de reforma bien distintas, y que se pueden sintetizar en cuatro puntos:

34 AGDT, «Representaciones...». Fray Blas Ortiz, 3 de mayo de 1803.

35 AGDT, "Representaciones...". Así se expresaba el murciano Luis de Campos. «Los choros de la religión —decía también- están desiertos de frailes, porque casi todos están dispensados, y los más de ellos mozos». 
- El regreso a la disciplina antigua, conforme a las intenciones de los Fundadores de las Religiones, ya que las constituciones de las órdenes, configuradas a lo largo de los sigios, han introducido los privilegios y las clases.

- Simplificar la organización interna de las religiones, esto es, abolir o aminorar privilegios y exenciones. Se promovía una nueva «vida en común» en la que superiores y súbditos debían ser iguales. En ningún caso se reclamaba la creación de vicarios nacionales pues, al fin y al cabo, dichos vicariatos eran una escala jerárquica más.

- La supresión de algunos conventos y la reducción del número de religiosos. Se entiende que sería beneficioso secularizar a los que no tenían vocación. Los conventos que se mantuvieran deberían ser lo suficientemente numerosos como para garantizar la vida en comunidad, y la digna manutención de sus religiosos.

- En numerosas representaciones (aunque no en todas) se pedía también la sujeción de los religiosos a los obispos, dado que los prelados regulares eran incapaces de frenar la relajación disciplinar. En su consecuencia, no debía haber más superior que el prelado local, elegido por los religiosos bajo la supervisión del obispo.

¿Qué factores explican esta proliferación de memoriales en pro de una reforma de las órdenes regulares? Una explicación tradicional incidiría en la difusión de las «disolventes» ideas jansenistas en el interior de los claustros. También se podría decir que estos memoriales respondían al resentimiento personal de religiosos desplazados de los cargos directivos o que se trataba de exageraciones de moralistas ${ }^{36}$. Creemos, sin embargo, que las cosas son más complejas. Durante el siglo xvili se difundía en los medios eclesiásticos un nuevo concepto de religiosidad conocida como «Catolicismo ilustrado» 37 . Este catolicismo de tinte más racionalista invitó a muchos religiosos a interrogarse sobre la utilidad de la vida regular a la que se habían consagrado. Fruto de este análisis, se encontraron con una realidad que rara vez respondía a los deseos: si dentro de los claustros

36 Esta última interpretación es de Jean de Viguerie, Cristianismo y revolución. Cinco lecciones de historia de la revolución francesa. Madrid, Rialp, 1991, pág. 31. Debemos recalcar que la documentación utilizada en nuestro análisis no procede ni de testimonios de historiadores liberales ni de cartas de superiores o actas de definitorios, documentos que como bien indica Revuelta "tienen a menudo una finalidad de corrección y vigilancia que sólo nos da aspectos negativos». Manuel Revuelta González, La exclaustración, Madrid, B.A.C., 1976, pág. 48.

37 Los estudios más recientes ponen de manifiesto que el peso de estas ideas dentro del clero regular fue mucho mayor de lo que hasta ahora se ha creído. Vid. Pedro Riquelme Oliva, Iglesia y liberalismo. Los Franciscanos en el Reino de Murcia (1768-1840). Murcia, Espigas, 1993, págs. 80 ss. 
muchos compañeros carecían de vocación, y otros sólo codiciaban el poder para satisfacer sus ambiciones, fuera de ellos observaban que España se hallaba inmersa en una crisis política y social sin precedentes en el recuerdo colectivo. Ante una crisis de tales dimensiones, que también tenía un fuerte componente espiritual, la religiosidad tradicional no ofrecía soluciones convincentes. Desde la óptica de la nueva espiritualidad, menos formalista y más espiritual, estos religiosos trataron de adecuar sus institutos a los nuevos tiempos, y muchas veces encontraron la solución en el pasado, esto es, en el restablecimiento de la disciplina antigua ${ }^{38}$. A estos reformadores ni se les pasaba por la cabeza atacar a las órdenes religiosas, pero los inmovilistas, esto es, aquéllos que no querían cambiar sustancialmente el estado de cosas, los llamaron «jansenistas" y «enemigos de la Iglesia». Era un mensaje que calaba fácilmente: el reformador era el «heterodoxo», el «díscolo» y el «mal fraile». Sin embargo, y aunque resulte paradójico, si las denuncias de los reformadores revelaban con toda crudeza los graves defectos existentes dentro de las religiones, demostraban también que los claustros eran todavía focos vitales, donde había muchos religiosos honestos y comprometidos ${ }^{39}$.

De esta manera, el clero regular llegaba a la coyuntura de 1808 en medio de una mal disimulada crisis. Muchas de las ideas reformistas surgidas en el interior de los conventos (sujeción a los obispos, reducción de conventos, vida en común) iban a ser retomadas unos años después por las Cortes de Cádiz, pero éste no es un motivo suficiente para identificar a los reformadores con los liberales. En todo caso, esta similitud de planteamientos prueba que buena parte de las ideas reformistas defendidas durante la etapa revolucionarla estaban ya presentes en los años anteriores, aunque sólo la libertad de imprenta y la propia dinámica del régimen constitucional las presentaran ante la "opinión pública».

\footnotetext{
38 Señala Callahan que «reformadores y tradicionalistas partían de la misma percepción: reinaba la falta de fe y la inmoralidad en todas partes. Para ambos, España parecía una nación más pagana que cristiana (...) Ahora bien, había una diferencia fundamental. El movimiento reformista concebía la reforma institucional como el único medio para transformar a la Iglesia a fin de que pudiera realizar su misión espiritual de forma más eficaz. Para los tradicionalistas, por el contrario, la causa de las dificultades de la iglesia no era la corrupción de las instituciones eclesiásticas, sino la perversión moral de los hombres". CALLAHAN, William J., Iglesia, poder y sociedad en España. Madrid, Nerea, 1989, pág. 83.

39 TORRES AMAT recordaba que el cardenal Borbón recibió varios planes de reforma, que definió como «britlante testimonio de la ilustrada piedad que encerraban los claustros en el principio de este siglo». Añadía además: “ojalá que vieran algún día la luz pública y se desengañaran aquellos que tachan luego de jansenista o de enemigo de la religión a cuantos, imitando el zelo de todos los santos y sabios obispos de la Iglesia, claman como los Belarminos, Bonas, Gersones, etc, etc por la reforma de varios abusos que la Iglesia detesta y llora, y cuyo remedio mandó ya en el Concilio de Trento". Torres Amat, Félix, Vida del llmo. Señor Don Félix Amat, Arzobispo de Paimyra. Madrid, Imprenta Fuentenebro, 1835, pág. 102.
} 